\title{
EFFICACY OF ANTIOXIDANT WITH ALOE VERA GEL VERSUS INTRA-LESIONAL STEROIDS IN THE MANAGEMENT OF ORAL SUBMUCOUS FIBROSIS - A PROSPECTIVE COMPARATIVE STUDY
}

\author{
Muhammad Tahir, Asim Abbas, Faiz Ul Hassan Nawaz, Mohsin Raza*, Atif Rafique**, Muhammad Sohail Babar Niazi ${ }^{* * *}$ \\ Combined Military Hospital Malir/National University of Medical Sciences (NUMS) Pakistan, ${ }^{*}$ Combined Military Hospital Okara/National University of \\ Medical Sciences (NUMS) Pakistan, ${ }^{* *}$ Combined Military Hospital Multan/National University of Medical Sciences (NUMS) Pakistan, \\ ${ }^{* * *}$ Combined Military Hospital Peshawar/National University of Medical Sciences (NUMS) Pakistan
}

\begin{abstract}
Objective: To compared efficacy of alpha lipoic acid (antioxidant medication) and aloe vera gel together versus intralesional steroids (hydrocortisone) in management of oral submucous fibrosis by evaluating post treatment clinical features of mouth opening and burning sensation.

Study Design: A prospective comparative study.

Place and Duration of Study: Department of ENT, Combined Military Hospital, Malir Karachi, from Jul 2018 to Mar 2020.

Methodology: Twenty-eight patients were involved in the research and were distributed into two groups, I and II. Alpha lipoid acid with aloe vera gel was given in group I and hydrocortisone was given in group II. Burning sensation and mouth opening were recorded both at start and at monthly interval later on for three consecutive months. The data collected were statistically analyzed by using SPSS-22.

Results: A significant lessening in burning sensation $(p<0.001)$ and improvement in mouth opening were noticed in both groups. However, comparison between alpha lipoic acid with aloe vera gel group versus hydrocortisone group showed almost similar results.

Conclusion: Alpha lipoic acid and aloe vera gel can significantly improve oral submucous fibrosis clinically. So, these can be utilized as an alternative option in cases where intralesional steroid is poorly tolerated or is contraindicated.
\end{abstract}

Keywords: Alpha lipoic acid, Aloe vera gel, Hydrocortisone, Intra-lesional steroids, Oral submucous fibrosis.

How to Cite This Article: Tahir M, Abbas A, Nawaz FH, Raza M, Rafique A, Niazi MSB. Efficacy of Antioxidant with Aloe Vera Gel Versus Intra-Lesional Steroids in The Management of Oral Submucous Fibrosis - A Prospective Comparative Study. Pak Armed Forces Med J 2021; 71 (Suppl-3): S526-529. Doi: $\quad$ Dttps://doi.org/10.51253/pafmj.v1i1.7921

This is an Open Access article distributed under the terms of the Creative Commons Attribution License (https://creativecommons.org/licenses/by-nc/4.0/), which permits unrestricted use, distribution, and reproduction in any medium, provided the original work is properly cited.

\section{INTRODUCTION}

Oral submucous fibrosis (OSMF) is a chronic, irreversible, progressive and debilitating collagen metabolic disease whichis brought by areca nut chewing and leads to blanching and stiffness oforal mucosa, pharynx and esophagus bringing a lot of functional morbidity clinically. ${ }^{1}$

The pathogenesis of OSMF is not fully understood, however it is assumed to be a disorder having multifactorial origins e.g., areca nut chewing, chilies ingestion, having genetic predisposition, involvement of different immunological processes and deficiencies of essential nutritional factors. When exposed to areca nut chewing, personswho are genetically susceptible develop this illness over a variable tenure of time. ${ }^{2}$

OSMF occurrence is increasing among the young age population especially in the their twenties as areca nut is available easily with less cost, in attractive packaging, and is marketed aggressively. ${ }^{3}$ It is estimated that OSMF prevalence ranges from $0.2-2.3 \%$ in men

Correspondence: Dr Muhammad Tahir, Department of ENT, Combined Military Hospital Malir Cantt Pakistan and $1.2-4.6 \%$ in women. ${ }^{4}$

Clinical features comprise of mild blanching and burning sensation in oral cavity at start while eating spicy foods. Later on, marble like appearances and fibrotic bands are seen at soft palate and buccal mucosa. As these fibrotic bands increase in size trismus starts to appear. In fully advanced disease leukoplakia and erythroplakia is seen along with dysphagia. ${ }^{5}$

OSMF is potentially premalignant condition. Progressively and permanently extracellular matrix starts getting deposited along with epithelial degeneration. It is a fibrotic disorder, which is mainly driven by a transforming growth factor- $\beta$ (TGF- $\beta$ ). ${ }^{6}$ Activation of TGF$\beta$ pathway is fundamental in progression of fibrosis in organs. It also plays main role in tumor development. Study conducted in Taiwan on 1 million premalignant lesionsof oral cavity cases retrospectively, shows a 10\% conversion ratio of OSMF to squamous cell carcinoma (SCC) of oral cavity in five to ten years after making a diagnosis. ${ }^{7}$

Areca/betel nut is used in numerous forms like gutka, paan masala and supari and is easily available 
in different areas of Karachi. Most of these preparations are contaminated by harmful bacteria and carcinogens like fungal aflatoxins. ${ }^{8}$ Risk of developing oral squamous cell carcinoma was found high, especially in female population of Pakistan. ${ }^{9}$

These days, Intralesional injections of steroids regimen is the most popularly applied protocol for OSMF, predominantly for those cases having palpable fibrotic bands in oral cavity. ${ }^{10}$

Although steroid injections are mainstay of treatment but these are very painful and leads to poor patient compliances as patient has to do repeated visit, secondly steroids have a lot of potential side effects. That's why we gave the hypothesis that OSMF can be treated equally well and even better by easily available oral antioxidants like alpha lipoic acid and aloe vera gel local application. This would give us a better and less invasive alternative to intralesional steroids in treating complicated disease like OSMF.

\section{METHODOLOGY}

Cases for the study were those who were referred to the ENT Department, Combined Military Hospital Malir Karachi, from July 2018 to March 2020. It was a prospective, single blinded, clinical study in which 28 patients were enrolled who presented with clinical features suggestive of OSMF. Permission for research was acquired from the Ethics Committee of institute

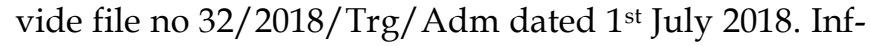
ormed written consent was obtained from each patient. Sample size was estimated, using sample size calculator where average estimated prevalence was 4 (1.75\%) and confidence level of $95 \%$ and margin of error was kept $5 \%$. A sample of $n=28$ cases of both genders, ageing 17-55 years with OSMF having history of addiction of areca, betel nut chewing having burning sensation on taking spices rich diet and having trismus with blanching, stiffness and palpable fibrotic bands in oral mucosa were included in study. Patients having active peptic ulcer, diabetes mellitus, tuberculosis, hypertension, temporo-mandibular joint disorders and cases that were allergic to drugs and refused to participate in study were excluded.

Afterthe diagnosis had been established, every single patient was informed about the precancerous potential of OSMF. Subjects were encouraged to stop the usage of tobacco and areca nut.

Kirankumar et al, classification, 11 was used for trismus: "Stage I: Mouth opening $>45 \mathrm{~mm}$ ”. "Stage II: Restricted mouth opening 20-4 4mm". "Stage III:
Mouth opening $<20 \mathrm{~mm}^{\prime \prime}$. The cases were placed in two groups randomly.

In Group I: alpha lipoic acideither $300 \mathrm{mg}$ (twice daily) or $600 \mathrm{mg}$ (once daily) was administered for 3 months and about one teaspoonful of aloe vera gel were locally applied 3 times a day for three months. Patients were advised to avoid eating or drinking for fifteen minutes after applying the aloe vera gel.

In Group II: Intralesional hydrocortisone (SoluCortef) $100 \mathrm{mg}$ mixed with lignocaine was injected bi weekly for three months.

Bothgroups were evaluated, in regard to mouth opening and burning sensation before the start of treatment and at monthly intervals during the treatment period of twelve weeks.

It was a prospective, single blinded, clinical study. The participants were designated a group using a chit scheme. Chits showing group I or II were kept in a carton. Each participant was requested to pick a chit blindly. On that basis, participants were allocated to either of two groups (I or II).

Mouth opening was objectively determined using a ruler by measuring "distance from the mesioincisal edge of the upper right central incisor to the mesioincisal edge of the lower right central incisor". The measurements were documented in millimeters (mm).

The burning sensation intensity was recorded by utilizing a Visual Analog Scale (VAS) of 0-10. Here, 0 showed no perception of burning sensation and 10 depicted the worst thinkable burning sensation. This all was documented before start of therapy and subsequently at monthly basis. This all was noted on the basis of patient's subjective reply.

Collected data was entered in SPSS version 22 for statistical analysis. All quantified variables in the research, i.e. mouth opening, duration of habit, burning sensation and age were analyzed for mean and standard deviation and was subjected to statistical analysis. The qualitative variables are presented in percentages. The independent sample $t$-test was utilized for assessment of the statistical significance of pre and post treatment mouth opening measurement and burning sensation values between the two groups. Paired sample t-test was used for evaluating the statistical significance of mouth opening and burning sensation between months within the each group. $p$-value was set at 0.05 and was regarded highly significant at $<0.01$. 


\section{RESULTS}

In this research, 28 cases of OSMF were selected and were randomly placed in one out of twogroups. Group I, the experimental group, revealed mean age of $26.14 \pm 5.33$ years. Group II, the controlled group, revealed mean age of $26.93 \pm 5.533$ years. No statistical significant difference was noted, in regard to age of patients between the two groups $(p=0.339)$. The bulk of patients were males in two groups.As far as gender is concerned, no statistically significant difference between group is noted $(p=0.622)$. Mean duration of habit of chewing areca nut was $11.39 \pm 3.79$ years in both groups. The more the duration of habit, the higher was the stage of disease. So the correlation between stage of disease and duration habit was found statistically significant $(p=0.002)$. The number of males were 23 $(82.1 \%)$ and females were $5(17.9 \%)$ in the study.

In Group I, mean mouth opening was $25.71 \mathrm{~mm}$ while In Group II, it was $25.50 \mathrm{~mm}$ at start of therapy. The pretreatment mouth opening difference, observed between two groups, was not statistically significant $(p=0.921)$.

Table-I: Demographics.

\begin{tabular}{|c|c|c|c|}
\hline & Group I & Group II & $p$-value \\
\hline Age (Years) & $26.14 \pm 5.33$ & $26.93 \pm 5.533$ & $0.339^{*}$ \\
\hline \multicolumn{4}{|l|}{ Gender } \\
\hline Male & $11(78.5 \%)$ & $12(85.7 \%)$ & \multirow{2}{*}{$0.622^{*}$} \\
\hline Female & $3(21.5 \%)$ & $2(14.3 \%)$ & \\
\hline $\begin{array}{l}\text { Duration of } \\
\text { Habit (Years) }\end{array}$ & $10.4 \pm 3.433$ & $12.14 \pm 4.111$ & $0.304^{* *}$ \\
\hline \multicolumn{4}{|c|}{ Stage of Disease } \\
\hline Stage II & $9(64.2 \%)$ & $12(85.7 \%)$ & \multirow{2}{*}{$0.19^{*}$} \\
\hline Stage III & $5(35.7 \%)$ & $2(14.3 \%)$ & \\
\hline
\end{tabular}

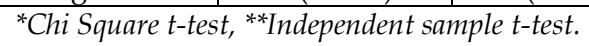

After the start of treatment regimens, gradual improvement in mouth opening, was seen in both of groups, which was recorded objectively on monthly basis and was found highly significant $(p=0.001)$ as shown in Table-II. However post treatment, result comparison between two groups (I and II), was not found statistically significant $(p=0.694)$.

Pre-treatment and post treatment burning sensation score revealed significant difference with $p \leq 0.001$ in group I showing significant improvement. Similarly in group II, the burning sensation improved significantly after completion of therapy $p \leq 0.001$, as shown in Table-III. No significant pre-treatment $(p=0.149)$ and post-treatment $(p=0.429)$ burning sensation intensity difference was seen between groups.
Table-II: Improvement in mouth opening.

\begin{tabular}{|c|c|c|c|c|}
\hline & Mean & SD & $\begin{array}{c}\text { t- } \\
\text { value }\end{array}$ & $\begin{array}{c}p \text { - } \\
\text { value }\end{array}$ \\
\hline \multicolumn{5}{|c|}{ Mouth Opening in mm Group I } \\
\hline At beginning of therapy & 25.71 & 4.340 & - & - \\
\hline After one month & 29.71 & 4.304 & -7.342 & 0.001 \\
\hline After two months & 34.29 & 4.232 & -11.368 & 0.001 \\
\hline After three months & 40.57 & 3.056 & -12.132 & 0.001 \\
\hline \multicolumn{5}{|c|}{ Mouth Opening in mm Group II } \\
\hline At beginning of therapy & 25.50 & 7.803 & - & - \\
\hline After one month & 30.07 & 6.522 & -9.582 & 0.001 \\
\hline After two months & 34.14 & 6.359 & -10.582 & 0.001 \\
\hline After three months & 40.00 & 4.420 & -8.850 & 0.001 \\
\hline \multicolumn{5}{|c|}{ Table-III: Improvement in burning sensation. } \\
\hline & Mean & SD & $\begin{array}{c}\text { t- } \\
\text { value }\end{array}$ & $\begin{array}{c}p- \\
\text { value }\end{array}$ \\
\hline \multicolumn{5}{|c|}{ Burning Sensation in Group I } \\
\hline At beginning of therapy & 6.71 & 0.994 & - & - \\
\hline After one month & 4.71 & 0.914 & 13.791 & 0.001 \\
\hline After two months & 3.00 & 0.961 & 10.494 & 0.001 \\
\hline After three months & 0.64 & 0.745 & 7.870 & 0.001 \\
\hline \multicolumn{5}{|c|}{ Burning Sensation in Group II } \\
\hline At beginning of therapy & 7.36 & 1.277 & - & - \\
\hline After one month & 4.64 & 1.277 & 13.986 & 0.001 \\
\hline After two months & 2.79 & 1.051 & 9.02 & 0.001 \\
\hline After three months & 0.86 & .663 & 7.870 & 0.001 \\
\hline
\end{tabular}

\section{DISCUSSION}

OSMF is a precancerous condition and its prevalence is gradually increasing over the period of time. ${ }^{12}$ So search for new regimens to cure this disease is of utmost importance. We studied the role of antioxidant alpha lipoic acid along with aloe vera gel in this research and compared the results with standard medication of intralesional steroids. Most of patients were male in this study that is in accordance with study carried out by Yang et al,12 in Taiwan which also showed that OSMF is more prevalent in males.

Bulk of our patients were in $2^{\text {nd }}$ decade of life that is similar to results found in study conducted by Bhatt et $a l^{13}$ where maximum patients were between 26-30 years of age. Probably this is because of increase in popularity of areca nut usage in Karachi and surrounding area among the young population. Areca nut is easily available and accessible to students as it is sold by street hawkers in front of schools. ${ }^{14}$

The longer the duration of habit; the higher the stage was found in this research that is in accordance to research carried out by Siddique et al..$^{15}$ The severity of OSMF was found positively correlated with duration of gutka intake.

Alpha lipoic acid is a strong antioxidant drug. It is used as first line therapy in OSMF. It is both water and 
fat soluble. So it removes free radicalsfrom both fat and water mediums and is especially useful in removing resistant free radicals from body. ${ }^{16}$ In our study, significant improvement was seen in mouth opening and burning sensation that is comparable to results seen in study conducted in Manglore, India by Rao. ${ }^{17}$ Similar results were also seen in another study, where they found alpha lipoic acid (thiocetic acid) extremely useful in treating OSMF.18 We also used aloe vera gel which was found extremely useful to treat OSMF in many studies. ${ }^{19-21}$

Intra lesional steroids are corticosteroids which are injected locally in oral mucosa where palpable fibrous bands are seen. This is most popular intervention, carried out these days in OSMF. Their use is especially justified in improving mouth opening. ${ }^{22}$

But problem is that they are very painful and have lot of potential side effects that's why we studied alpha lipoic acid and aloe vera gel and found them equally useful and efficacious.

\section{LIMITATION OF STUDY}

A few limitations in this research were noted. The length of research was only three months; an extended follow up studies, with bigger sample size should be carried out to find out any long-term special effects of alpha lipoic acid and aloe vera gel. High cost of alpha lipoic acid was a limiting factor in this study.

\section{CONCLUSION}

Alpha lipoic acid and aloe vera gel showed promising results as they brought about significant improvement in mouth opening and burning sensation of OSMF. So can be used as, a preferred alternative to intralesional steroids.

\section{Conflict of Interest: None.}

\section{Authors' Contribution}

MT: Manuscript drafting, literature survey \& bibliography, data interpretation, AA: Conceived the main research idea \& developed the study design, developed the study tool, FHN: Data collection \& analysis, inter-preatation of results and tabulation, final proof reading for grammatical or language errors, MR: Helped in data collection, data entry and analysis, AR: Research supervisor, cirticla checking and analysis of the results, final approval of the manuscript, MSBN: Data collection \& analysis, interpreatation of results and tabulation, final proof read for grammatical or language errors.

\section{REFERENCES}

1. More CB, Rao NR. Proposed clinical definition for oral submucous fibrosis. J Oral Biol Craniofac Res 2019; 9(4): 311-314.

2. Ray JG, Chatterjee R, Chaudhuri K. Oral submucous fibrosis: a global challenge. Rising incidence, risk factors, management, and research priorities. Periodontol 2000; 80(1): 200-212.

3. Alexander AJ, Ramani P, Sherlin HJ, Gheena S. Quantitative analysis of copper levels in areca nut plantation area-A role in increasing prevalence of oral submucous fibrosis: An in vitro study. Ind J Dent Res 2019; 30(2): 261-265.

4. Rao NR, Villa A, More CB, Jayasinghe RD, Kerr AR, Johnson NW. Oral submucous fibrosis: a contemporary narrative review with a proposed inter-professional approach for an early diagnosis and clinical management. J Otolaryngol Head Neck Surg 2020; 49(1): 1-1.

5. Passi D, Bhanot P, Kacker D, Chahal D. Oral submucous fibrosis: Newer proposed classification with critical updates in pathogenesis and management strategies. Natl J Maxillofac Surg 2017; 8(2): 89-92.

6. Pant I, Rao SG, Kondaiah P. Role of areca nut induced JNK/ATF2/ Jun axis in the activation of TGF- $\beta$ pathway in precancerous Oral Submucous Fibrosis. Scientific Rep 2016; 6(1): 34314.

7. Lian IB, Tseng YT, Su CC, Tsai KY. Progression of precancerous lesions to oral cancer: results based on the Taiwan National Health Insurance Database. Oral Oncol 2013; 49(5): 427-430.

8. Sulaiman A, Zuberi HS, Irfan S, Ghias K. Microbiological safety of areca nut-containing, ready-to-eat chewing substances common among Pakistani paediatric population: A pilot study. JPMA. J Pak Med Assoc 2019; 69(3): 450-455.

9. Mohiuddin S, Fatima N, Hosein S, Hosein M. High risk of malignant transformation of oral submucous fibrosis in Pakistani females: A potential national disaster. J Pak Med Assoc 2016; 66(11): 1362-1366.

10. Tilakaratne WM, Ekanayaka RP, Herath M, Jayasinghe RD, Sitheeque $\mathrm{M}$, Amarasinghe $\mathrm{H}$. Intralesional corticosteroids as a treatment for restricted mouth opening in oral submucous fibrosis. Oral Surg Oral Med Oral Pathol Oral Radiol 2016; 122(2): 224-231.

11. Kumar KK, Saraswathi TR, Ranganathan K, Devi MU, Elizabeth J. Oral submucous fibrosis: A clinico-histopathologicalstudy in Chennai. Indian J Dent Res 2007; 18(3): 106-108.

12. Yang SF, Wang YH, Su NY, Yu HC, Wei CY, Yu CH, et all. Changes in prevalence of precancerous oral submucous fibrosis from 1996 to 2013 in Taiwan: a nationwide population-based retrospective study. J Formos Med Associat 2018; 117(2): 147-152.

13. Bhatt $P$, Manjunath $M$, Khakhla $D$, Gubrellay $P$, Bhargava $R$, Guruprasad L. Assessment and correlation between functional and histological staging of oral submucous fibrosis: A clinicohistopathologic study. Natl J of Maxillofac Surg 2019; 10(1): 27-30.

14. Hussain A, Zaheer S, Shafique K. Individual, social and environmental determinants of smokeless tobacco and betel quid use amongst adolescents of Karachi: a school-based cross-sectional survey. BMC Public Health 2017; 17(1): 913-915.

15. Siddiqui HK, Khan FR, Sadiq A, Hashmi U, Qaiser Z. Predictors of the severity of oral submucous fibrosis among gutka consumers: a regression analysis. Br J Oral Maxillofac Surg 2021; 59(6): 690-694.

16. Rajakumar P, Saravanan R, Prabhakar R, Kumar RV, Abinesh S, Vivakanandhan U. Role of Antioxidants in Oral Submucous Fibrosis. J Int Oral Health 2016; 8(3): 412-415.

17. Rao PK. Efficacy of alpha lipoic acid in adjunct with intralesional steroids and hyaluronidase in the management of oral submucous fibrosis. J CanRes Ther 2010; 6(4): 508-511.

18. Bhandarkar GP, Shetty KV, Kulkarni A. Thioctic acid in oral submucous fibrosis (India's disease)-A better tomorrow. J Stomatol Oral Maxillofac Surg 2018; 119(2): 129-134.

19. Sudarshan R, Annigeri RG, Sree Vijayabala G. Aloe vera in the treatment for oral submucous fibrosis-a preliminary study. J Oral Pathol Med 2012; 41(10): 755-761.

20. Anuradha A, Patil B, Asha VR. Evaluation of efficacy of Aloe vera in the treatment of oral submucous fibrosis-a clinical study. J Oral Pathol Med 2017; 46(1): 50-55.

21. Patil S, Al-Zarea BK, Maheshwari S, Sahu R. Comparative evaluation of natural antioxidants spirulina and aloe vera for the treatment of oral submucous fibrosis. J Oral Biol Craniofac Res 2015; 5(1): 11-15.

22. Tilakaratne WM, Ekanayaka RP. Intralesional corticosteroids as a treatment for restricted mouth opening in oral submucous fibrosis. Oral Surg Oral Med Oral Pathol Oral Radiol 2016; 122(2): 224-231. 